\title{
¿Existe un matriarcado afrodescendiente en Chile? Un estudio etnográfico con mujeres afrochilenas del valle de Azapa.
}

\author{
Is there an Afro-descendant matriarchy in Chile? An ethnographic \\ study with Afro-Chilean women from the Azapa valley.
}

Nicole Chávez González*

\section{Resumen}

Este artículo aborda el estudio de mujeres afrochilenas del valle de Azapa, poseedoras de ascendencia africana en un país que, hasta la actualidad, niega su existencia como población diferenciada, bajo la articulación de conceptos como raza y racialización. Por ello, se relevará la importancia que la población femenina ha tenido a lo largo de la historia de su comunidad, desde el período de la esclavización hasta la actualidad, como actrices primordiales en la reconstrucción de dinámicas identitarias, por medio de la memoria, la oralitura, y las resistencias generadas en diferentes espacios socio-culturales y políticos. De esta manera, se pone en discusión el grado de relevancia que tienen dentro de la comunidad afro en el valle, particularmente con la celebración religiosa de la "Cruz de Mayo". Existen potencias femeninas del valle llamadas matriarcas; son ancestras reconocidas como Julia Corvacho y Flora Cardoso, por mencionar algunas. Desde allí resaltan los lazos de parentesco como posicionamientos sociales de las afroazapeñas, en este posible sistema de matriarcado.

Palabras claves: afrochilenas, género, matriarcado, etnografía, valle de Azapa.

\begin{abstract}
This article addresses the study of afrochilean women from Azapa valley, as having african descent in a country that to date denies their existence as a differentiated population, under the articulation of concepts such as race and racialization. For this reason, the importance of the female population had throughout the history of their community, from the period of enslavement to the present, will be highlighted as primordial actresses in the reconstruction of identity dynamics through memory, oral writing, and the resistance generated in different spaces socio-cultural and political. In this way, the degree of relevance that they have within the afro community in the valley is questioned, particularly the "Cruz de Mayo" religious celebration. There are some female powers of the valley, called matriarchs; They are the recognized ancestors: Julia Corvacho, and Flora Cardoso, to name a few. From there, the

\footnotetext{
Estudiante de Doctorado en Sociología, Pontifica Universidad Católica, Chile. Becaria ANID, Doctorado Nacional, 2021, folio 21210961. Magister ( en Antropologías Latinoamericanas, Universidad Chilena de Estudios Afro. Mail: nicolechg88@gmail.com
} Alberto Hurtado, Chile. Becaria Fondart Nacional 2019. Licenciada en Antropología, Universidad Academia de Humanismo Cristiano. Investigadora de Kuriche (www.kuriche.cl) y parte de la Red
\end{abstract}


kinship ties stand out as the social positions of the afroazapeñas in this possible system of matriarchy.

Keywords: afrochilean, gender, matriarchy, ethnographies, Azapa valley

Fecha de recepción: Mayo 2021

Fecha de aprobación: Diciembre 2021

\section{Introducción ${ }^{1}$}

En Chile existe un silenciamiento sistemático de las culturas afrodescendiente en general, lo que lleva al desconocimiento de quienes habitaron y habitan en este territorio. A esto se suma la negación de la presencia y participación de las mujeres africanas (y sus descendientes), las que sufren una triple discriminación: raza ${ }^{2}$, género y clase. Respecto al abordaje académico de estas temáticas, algunas autoras chilenas como Rosa Soto ${ }^{3}$, Paulina Barrenechea y Viviana Briones, entre otras, se basan generalmente en el período de esclavización/colonización (s.XV-s.XVIII) en el país, sin embargo, la información continúa siendo escasa para las décadas posteriores. Asimismo, la propia comunidad afrodescendiente ha generado material, tal es el caso de Marta Salgado, Carolina Cortés y Azeneth Báez, quienes en sus libros, tesis y artículos recopilan sus propios saberes (Chávez, 2021).

En palabras de Barrenechea, a partir de la negación de la identidad negra en Chile, comienza un emergente movimiento de auto-reconocimiento -en el marco de los 90's, con el surgimiento de la re-etnitización de los pueblos indígenas y valorización de la diferencia en el continente- a través de nuevas generaciones que se posicionan como afrochilenos/as (2005). Varios estudios señalan que el movimiento afrodescendiente chileno del norte del país específicamente en la región de Arica y Parinacota ${ }^{4}$ - surge el año 2001, pero sólo después de 20 años logran ser reconocidos legalmente por la "Ley del Pueblo Tribal Afrodescendiente"5, promulgada el año 2019. Este proceso de re-etnificación o etnogénesis (Bengoa, 2004) ${ }^{6}$,

\footnotetext{
${ }^{1}$ Este artículo se basa en diferentes investigaciones colaborativos realizados desde mi tesis de licenciatura en Antropología (UAHC), llamada "Mujeres afrodescendientes chilenas, raíces africanas en el Valle de Azapa y Arica" (2016), al igual que mi tesis de magister en Antropología Latinoamericanas $(\mathrm{UAH})$, denominada "Cruz de Mayo afroandina: prácticas religiosas y dinámicas identitarias afrodescendiente e aymara en el valle de Azapa, Arica" (2021).

${ }^{2}$ La raza ha sido concebida como una idea y/o categoría social de poder y opresión basada en ideologías fenotípicas creadas (Curiel, 2017).

${ }^{3}$ Una importante historiadora referente sobre negras esclavizadas, fallecida este 2021. Expreso mis admiraciones y gratitud por sus enseñanzas.

${ }^{4}$ Esta región se ubica en el extremo norte del país, limita con Perú y Bolivia. Originalmente territorio del Perú, ocupado por el ejército chileno durante la Guerra del Pacífico. En 1929 se cedió definitivamente Arica a Chile.

${ }^{5}$ Ver https://www.leychile.cl/Navegar?idNorma=1130641 (Visitado el 2 de marzo 2021)

${ }^{6}$ Aborda el proceso de reconstrucción de las identidades y su constitución como grupos étnico-racial en nuestro país.
} 
comienza en el momento en que Sonia Salgado ${ }^{7}$ y su hermana, Marta, asistieron a la "Conferencia Preparatoria de las Américas Contra el Racismo, la Discriminación Racial y la Xenofobia", organizada por las Naciones Unidas en Santiago de Chile, y fueron las primeras en exclamar de manera pública: "¡Existimos los negros, nosotros somos negros!” (Salgado, 2013, p. 4). A continuación, promueven la movilización en Arica, creándose la Organización No Gubernamental (ONG) "Oro Negro", entre otras múltiples organizaciones en la ciudad, así como también en el valle de Azapa con (ONG) "Lumbanga". Hasta la actualidad, no existen datos censales sobre la comunidad afro; la única cifra es antigua y se basa en la "Encuesta de Caracterización Afrodescendiente" realizada por el Instituto Nacional de Estadística (INE) el año 2013, que dio como resultado que un 4,7\% de la población regional de Arica y Parinacota se autorreconoció como tal. En esta misma encuesta se sostiene que la composición sociodemográfica "corresponde a 3.719 hombres y 4.696 mujeres equivalentes a un $44,2 \%$ y $55,8 \%$, respectivamente" (INE, 2013, p. 14). A partir de estos datos, pese a la poca diferencia estadística, me pregunto: ¿Es casualidad que más población femenina se reconozca afrodescendiente que la masculina?

Actualmente la comunidad afro en Chile se instala mayoritariamente en Arica y en el valle de Azapa, ubicado a unos cinco kilómetros de la ciudad. La zona de Azapa destaca porque durante la colonización proliferaron las plantaciones de caña de azúcar y algodón, quehaceres realizados por mano de obra esclavizada. Esta zona es altamente fértil y posee una gran variedad de producción agrícola. A lo largo del valle encontramos la localidad de San Miguel de Azapa (km 12-13) y sectores como: Pago de Albarracín ${ }^{8}$, Alto Ramírez, La Corvachada, Las Maytas, Pago de Gómez, Azapa Grande, La Rivera, entre otros, reconocidos por su alta población afro (Salgado, 2013).

El propósito de este artículo es analizar la relación entre género, parentesco y dinámicas afro a través de la figura de las ancestras, por medio de la re-significación de memorias y transmisión de costumbres, ejemplificado con el caso de una celebración religiosa Ilamada Cruz de Mayo. Festividad popular que se celebra en Latinoamérica y Chile, pero en esta zona tiene particularidades debido a la interrelación entre lo católico, lo indígena y lo afro (Araya, Chávez y Alarcón, 2019). El objetivo es reivindicar el lugar de mujeres racializadas, desde las "abuelas" "llamadas matriarcas, en su mayoría del valle de Azapa. Las afrochilenas del norte poseen roles históricos desde la esclavización, la conformación de Estado-Nación, proceso de chilenización, hasta la actualidad, quienes han utilizado diferentes estrategias para sobrevivir y apoyar a sus comunidades desde roles privados y públicos como lideresas de diferentes organizaciones socio-culturales y políticas (Cortés y Rivera, 2019). En particular, este escrito surge de ver una relación entre género y afrodescendencia azapeña, que se expresa en múltiples espacios, siendo uno de ellos la Cruz de Mayo, pues la mayoría de las cruces reciben el nombre de las matriarcas de las familias que las festejan, como: Julia Corvacho, Eulogia Baluarte, Flora Cardoso, Tomasa Baluarte, Lucía Huanca y Julia García, por mencionar algunas. La relación de las familias con sus ancestras/matriarcas es un aspecto

\footnotetext{
${ }^{7}$ Alcaldesa de Camarones en ese momento, comuna que pertenece a la provincia de Arica.

8 Tanto Albarracín como Corvacho, son apellidos afro reconocidos como propios.

${ }^{9}$ No se utiliza el término de modo peyorativo, sino que es el modo en que las y los afro se refieren a adultos mayores.
} 
relevante: ¿Por qué la comunidad afrochilena honra a sus ancestras? ¿Qué procesos históricos llevan a esto?

En Arica y en el valle de Azapa, la visibilidad de las afrochilenas se ha vinculado a la lucha por el reconocimiento frente al Estado, una reivindicación que ha estado subsumida a la lucha del colectivo. Sin embargo, en los últimos años la arista femenina ha tomado mayor peso y se han consolidado en colectivas feministas, desde una feminidad negra resignificada, antirracista y antisexista, que las convierte en agentes políticas capaces de hacer transformaciones sociales, al ser partes de diferentes proyectos de resistencia desde sus propias visiones (Espinosa, 2014). En este sentido, que las mujeres, reconocidamente, ejerzan posiciones importantes en la estructura de sus comunidades y sean un elemento primordial en las familias, me hace reflexionar sobre un potencial matriarcado (Martín-Cano, 2005). Finalmente, el valor de este trabajo es describir y reivindicar los roles de las mujeres afro en el norte del país, desde un análisis histórico- procesual, mediante el cual se destaca cómo esta población femenina ha resistido y mantenido viva a una comunidad, a pesar de diferentes sucesos de genocidio físico y cultural acaecidos sobre sus culturas.

A continuación, veremos una conceptualización metodológica y teórica basada en conceptos como género, matriarcado, memoria y resistencia, para posteriormente presentar los hallazgos históricos y etnográficos sobre los roles de estas mujeres en el valle de Azapa desde la colonización/esclavización hasta el presente. De esta manera, se exponen diferentes espacios de transmisión de saberes y prácticas que escapan de las convenciones sociales hegemónicas y articulan sus identidades como mujeres intelectuales, autoridades locales y familiares, relevante en lo laboral y económico con las "comerciantas" ${ }^{10}$, asimismo en lo político y poseedoras de terrenos, donde destaca su relación con la agricultura y la tierra, lo culinario, la artesanía y danzas, lo religioso, junto con sus aportes en el movimiento político (Chávez, 2016). Finalmente, se abordan reflexiones sobre la posible existencia de un matriarcado afroazapeño, pues la suma de estos puntos marcan también los sistemas de parentesco y lazos sociales de esta comunidad.

\section{Aproximación metodológica y teórica}

En cuanto a la metodología, los resultados de este artículo se basan en una investigación cualitativa enfocada en la etnografía desde la antropología. Las principales fuentes de información se sustentan en trabajos en terreno y diarios de campo realizados entre los años 2014-2021, herramientas que permiten adentrarse en las vidas de las comunidades afro y en específico, de la población femenina, convivir cotidianamente con ellos, participar en sus actividades y observar sus realidades. Junto a entrevistas en profundidad y relatos de vida con la comunidad afrochilena, específicamente con población femenina. Tanto para las entrevistas presenciales como las de vía remota debido al COVID19, hubo preguntas estructuradas, pero más bien fueron conversaciones reflexivas e intencionadas con un objetivo claro a investigar. De esta manera, los datos provienen de la

${ }^{10}$ Este artículo adopta un lenguaje inclusivo de género. 
vida cotidiana, del sentido común, de las explicaciones y reconstrucciones que las mismas personas efectúan.

Estas características porosas de mixturas entre quehaceres y modos de hacer, me servirán para explicar conflictos sobre autoridad, jerarquías y colonización del pensamiento teórico-empírico, que empujan mi posicionamiento y reflexión acerca del uso de metodologías participativas y/o colaborativas, donde las y los interlocutores posean una importancia clave en la investigación, para dejar de entenderlos como meros facilitadores de datos, sino que como partícipes en el proceso de co-interpretación (Lassiter, 2005). Esta selección es pragmática, estratégica y auto-reflexiva; tiene como base las distinciones, procesos, cercanías y mejor entendimiento con las comunidades. Desde mis primeras investigaciones aposté por un trabajo en el que existiera; a) la devolución de la información: con sesiones explicativas, entrega de fotografías, grabaciones, materiales como también de los productos finales emanados de los estudios, y b) una co-construcción de saberes: invitación a las comunidades a participar directamente y que se impliquen de modo interactivo en la investigación, con actividades tales como lectura de avances, fotografías y relatos propios, entre otros. Entiendo la colaboración como un proceso de construcción de saber socio-político y de compromiso de transformación acción-colectiva.

Desde entonces he desarrollado diferentes investigaciones con perspectivas de género y raza, siempre abierta al diálogo para aprehender de las colaboradoras (Katzer y Samprón, 2011). La etnografía colaborativa se convierte en un punto de partida para una acción en movimiento, no es sólo un producto final, sino un proceso de aprendizaje continuo. Una de las maneras de realizarlo es con teorías feministas interseccionales y decoloniales que ponen el foco en aspectos sobre relaciones de poder y de la representación para evitar la complicidad en la (re) producción de conocimientos (re) colonizados, por medio del intercambio de ideas en un diálogo continuo (Lassiter, 2005). Ello contiene una implicación personal y de responsabilidad mutua, la colaboración y el compromiso social están en el corazón del quehacer y proceso etnográfico, como principio explícito y guía del estudio, a través de una construcción colectiva. Bajo esta línea, y desde estrategias colaborativas, se trabajó desde una mirada que comprende a las afrochilenas como agentes activas. Por último, quisiera destacar que mi posicionamiento como mujer feminista decolonial y mi reflexividad ${ }^{11}$ como investigadora han sido constante dentro de mis procesos personales de politización y activismo $^{12}$, al igual que los aprendizajes adquiridos con las múltiples experiencias con mujeres afro en Chile, desde un compromiso de acción colectiva (Guber, 2014). Desde allí destaco que las y los interlocutores son personas que confían, se abren y nos invitan/permiten sumergirnos en sus vidas, por ende, muchas veces creamos vínculos de cercanía, amistad y de compartir experiencias significativas.

\footnotetext{
${ }^{11}$ Personalmente, cada investigación posee una implicación recíproca y de articulaciones con las y los colaboradores, como también un posicionamiento discursivo, activista y movilizador en aras de aportar a las comunidades para que les sirva de apoyo en lo que estimen conveniente.

${ }^{12}$ En mi caso ha consistido en ser parte de Kuriche (www.kuriche.cl), un núcleo de estudios de temáticas afro en Chile, donde realizamos talleres, charlas, distribución de información y trabajos con la comunidad afrochilena y de la diáspora.
} 
Respecto a lo teórico, abordo el género ${ }^{13}$ y la raza desde una crítica decolonial, como aspectos históricos de dominación dentro de la colonización del poder; además, se les otorga estatutos epistémicos como categorías centrales para transformar aspectos que se les han impuesto a algunas comunidades, subyugadas bajo el cristal del patriarcado y de la raza (Segato, 2010; Lugones, 2008). En este análisis se discuten los trabajos de académicas que sobresaltan diferentes estrategias de politización y resistencia de mujeres negras sobre el impacto del capitalismo esclavista, colonialista y extractivista, de la heterosexualidad obligatoria, de la marginalización y la violencia colonial epistémica (Hernández, 2019). El Feminismo Negro o "Black Feminism" como proceso nació en EEUU -Lorde, Davis, bell hooks, entre varias- quienes han luchado políticamente a nivel internacional, frente al racismo y sexismo que acaece sobre mujeres negras; ser de "color" más que una definición biológica, es una categoría política (Davis, 2004). Patricia Hill Collins, estableció el concepto social y teórico de interseccionalidad, que implica la transversalidad entre etnia, raza y clase, sobre aquellas situaciones de discriminación que han experimentado las negras, en cuanto a exclusión y sometimiento (1990). Sin embargo, y tal como expone Ardito (2021) este concepto en particular se ha popularizado al nivel de perder explicaciones que aborden su complejidad y quedan a merced de políticas que reproducen el mismo orden social, a través de mecanismos que no tienen un mayor peso en concreto para esta población.

Según diferentes autoras -Sueli Carneiro, Ochy Curiel, Yuderyks Espinosa, entre algunas- en Abya-Yala ${ }^{14}$ igualmente existe un movimiento de feministas antirracistas y decoloniales quienes señalan la existencia de un proceso de "ennegrecimiento" en la región (Carneiro, 2001), característica que las dotan de originalidad y que utilizan para potenciarse desde dentro y desde fuera de los feminismos contemporáneos actuales (Ardito, 2021). Las afro han sido silenciadas a lo largo de la historia, lo que las ha llevado a construir feminismos negros decoloniales, que cuestionan de raíz los ideales feministas blancos, occidentales, hegemónicos y academicistas pues ponen en evidencia el cruce de otras temáticas como el racismo, el colonialismo, y por consecuencia, procesos de discriminación racial, étnica, sexual y represiones que no es posible universalizar para las diferentes corporalidades racializadas (Chávez, 2021). No basta sólo con ser mujeres, pues cada una tiene sus objetivos, necesidades y demandas específicas (Curiel, 2017). Desde allí buscan una transformación social sobre estas estructuras imbricadas en diferentes contextos y situaciones particulares.

Las feministas negras racializadas producen una teorización que remite a las prácticas de sus culturas. A raíz de estos planteamientos, este grupo ha generado políticas antisexistas y antirracistas, que las constituyen como sujetas activas con una lucha política dentro de un proyecto de resistencia y reconceptualización de categorías. Las exigencias de este grupo de mujeres se basan en sus experiencias, y consisten en denunciar políticas públicas del Estado y de la misma ciudadanía que continúan replicando modelos racistas. Tanto en lo privado como en lo público, existió y existe la construcción de estereotipos, roles sexualizados y explotaciones desde diferentes campos (Curiel, 2007). Finalmente, se comprende el concepto

\footnotetext{
${ }^{13}$ Lamas sostiene que "el género es una construcción social, cultural e histórica" (1986, p. 194).

${ }^{14}$ Desde una perspectiva descolonizadora de las realidades socio-territoriales y geopolíticas de mujeres, se utiliza el concepto Abya-Yala, propuesto por feminismos críticos y situados de nuestro continente (Espinosa, 2016).
} 
de "mujeres racializadas" como categoría que visibiliza "un rol socialmente construido, productivo y reproductivo de fuerza de trabajo no remunerada, forzada o explotada, que ha sido invisibilizado, privatizado y naturalizado" (Ardito, 2021, p. 187), esto se evidencia en diferentes modos de reproducción social que se replican desde la esclavización hasta los días actuales.

Por otra parte, se expone el concepto de matriarcado, que tiene relación con un efectivo dominio de las mujeres, en respeto con la naturaleza como la "Gran madre procreadora ${ }^{15}$ ", que tiene como objetivo el encontrar una igualdad y fraternidad social (Annunziata, 2001).También planteo el controversial concepto de ginecocracia de Bachofen (1998), entendido como el derecho de honrar más a las mujeres que a los varones, adquirir apellidos de la madre y no del padre, la transmisión y herencia a sus infantes. Esto tiene relación con los llamados sistemas matrilineales, donde se sostiene que la adscripción de la persona con su linaje está determinada por vía materna y sus principales familiares son parientes de la madre, así mismo las propiedades y las herencias de tierras provienen de la familia del lado femenino (Martín-Cano, 2005). De este modo, las mujeres no sólo continúan con los lazos de parentesco y herencias, sino que también protegen la tierra y fecundan el campo, en consecuencia, la subsistencia de las comunidades. Incluso, se podría establecer un nexo con algunas sociedades africanas, donde las mujeres eran un bien preciado pues mediante ellas se adquirían posiciones y relaciones familiares, mientras que otros grupos de África Occidental se caracterizaban por una organización social matrilineal y matrilocal (Soto, 2001). Esto hace reconsiderar cuánto de estas tradiciones de orígenes africanas los y las esclavizadas conservaron y replicaron sobre sus descendencias en las zona de arribo a lo largo de Abya-Yala.

En cuanto a la memoria y resistencia, Marisol De la Cadena (1992) releva el concepto de "mujeres en resistencia", que en este artículo simboliza a las afrochilenas, quienes suelen conservar y transmitir las dinámicas y prácticas identitarias de sus pueblos más que los varones, a pesar de que ellas están más subordinadas al incorporar las diferencias de género. Klein (1986) sostiene que incluso desde la esclavización hasta la actualidad, es la población femenina quien crea vínculos de parentesco, especialmente en la crianza de infantes, pues esto va más allá de los clásicos estereotipos de socialización relacionados a roles de género, sino que es más bien "un proceso político, pues las mujeres desarrollan hacia las hijas y los hijos procesos de concientización que les da herramientas para enfrentar el racismo" (Curiel, 2007, p. 10), desde una lucha contra la discriminación que viven en los diferentes territorios. En definitiva, las memorias son fundamentales para mantener las identidades, y según los testimonios de las mujeres colaboradoras de esta investigación, son las abuelas y madres quienes difunden los recuerdos y costumbres. De esta manera, se construyen procesos de identidades y autorreconocimiento en relación con la raza y etnicidad (Hall, 1995) como si fueran un tejido de prácticas, lenguajes, símbolos y convivencia (Rivera Cusicanqui, 2010).

\footnotetext{
15 Se resalta también el "culto mariano" como una marca de los pueblos latinoamericanos en sus construcciones identitarias y el lugar que asignan a las madres, pero no se aborda en profundidad pues extiende la pregunta hacia un ámbito más amplio que lo afro, que es lo abordado en este artículo.
} 
Existen relatos compartidos que se verbalizan mediante la oralitura de distintos hitos del colectivo, entendido como la alusión a la comunicación que inscribe prácticas orales, sociales, rituales, entre otros, junto con el rol de la escritura en las comunidades afro (Mendizábal, 2012). Esto se despliega, en la importancia que les otorgan a sus ancestras, pues sostienen que fueron ellas quienes conservaron sus tradiciones afro desde sus hogares, como madres, educadoras de recién nacidos y dueñas de casa, en cuanto a transmisión de conocimientos y sociabilización sobre sus historias, gastronomías, ritos religiosos, danzas, que confluyen en la educación de futuras generaciones y enseñanzas asociales, físicas e intelectuales (Chávez, 2021).

\section{Hallazgos etnográficos: Prácticas de resistencias}

Desde que nosotras hemos sabido siempre han sido las mujeres. Nuestras ancestras han sido más empoderadas en luchar por no perder nuestra cultura. $Y$ han sido nuestras ancestras, no nuestros ancestros. (Entrevista Maggi, 2021) ${ }^{16 .}$

La llegada de colonizadores junto a la mayor trata transatlántica de millones de personas de África, no estuvo exentas de presencia femenina. Soto (2001) sostiene que se recomendó que trajeran negras a América para evitar el descontento de los varones esclavizados, pero la mayoría de ellas fueron vendidas a "amos" que las utilizaron para sus propios beneficios. Durante el siglo XVIII, según Briones (2007), el precio de una mujer era mayor que el de un varón debido a sus habilidades en el hogar; los principales oficios en los que se desempeñaban eran: costureras, lavanderas, matronas y "esclavas de razón ${ }^{17 "}$ ", pasando a ser parte de la fuerza laboral en las haciendas coloniales, en trabajos con jornadas excesivas y sujetas constantemente a malos tratos físicos y psicológicos (Soto, 1992). La esclavización, en su totalidad, estuvo colmada de malos tratos para ambos sexos. Sin embargo, las africanas fueron violentadas sexualmente, ya que eran vistas como fuente de pecado e imperaba un exotismo sobre ellas, aumentando la validación y normalización del abuso de muchos de los patrones por sobre las esclavizadas (Barrenechea, 2005). Fruto de estas vejaciones surgió el "mulataje"; la mezcla entre blanco y negra, un mestizaje que fue fuertemente sancionado y discriminado por la población colonial (Soto, 2001). En algunas ocasiones, las relaciones de criada-amo fueron usadas a su favor para el progreso social, aunque esto alargaba la continua dominación en la que quedaban cautivas de sus propietarios.

Las mujeres negras esclavizadas tuvimos mucha fuerza para poder o intentar mantener un núcleo familiar, la mujer paría, pero también abortaba mucho porque no querían tener hijos esclavizados, eran mujeres con mucha fuerza. (Entrevista Milene, 2015).

\footnotetext{
${ }^{16}$ Los nombres de las y los participantes son reales y cuentan con consentimiento para su uso. Las entrevistas nombradas fueron realizadas entre 2014 y 2020.

${ }^{17}$ Labor que consistía en transmitir de memoria los recados de hogar en hogar dentro la élite señorial.
} 
Por una parte, las mujeres eran utilizadas como vientres generadores; las convirtieron en "productoras y reproductoras de fuerza de trabajo" (Soto, 2001, p. 4), tanto ellas como sus infantes eran transados como mercancías -sexuales, reproductivas y productivas- que aumentaban el patrimonio esclavizador. De hecho, según Marta Salgado, escritora afrochilena, durante el siglo XVIII hubo un negocio muy fructífero de "criaderos de negros" en el valle de Lluta, en un sector conocido como "Muelle Pampa", camino a Poconchile (2013). En estos espacios el ser humano era visto como un producto, mientras que a las mujeres se le quitó la capacidad de autodeterminación sobre sus cuerpos y sucesores. Esto ocurría a nivel continental, pues Angela Davis, en EEUU, corrobora que "las esclavas entraban dentro de la categoría de "paridoras» y no de la de «madres», sus criaturas podían ser vendidas y arrancadas de ellas con entera libertad" (2004, p. 15). O la figura de las "ama de leite" en Brasil, que resalta Machado (2009) sobre mujeres esclavizadas que, separadas de sus hijas e hijos, criaban y alimentaban a lactantes de familias blancas. En contraparte, Briones rescata los roles de las mujeres en la reiterada petición de la manumisión de su progenie, pues si bien la condición de esclavizado/a era heredado por línea materna, fueron también ellas quienes lograron apelar a la condición de liberación para sus descendientes (2007). De esta manera, las negras estaban inmersas tanto en la resistencia cotidiana de una transgresión social y cultural, al mismo tiempo que su presencia denotaba una incidencia dentro del ámbito jurídico en la lucha por acuerdos de testamentos y libertad de sus descendientes, lo que revela configuraciones familiares que buscaban mantener la unidad (Soto, 1992). Tal como sostienen las colaboradoras:

Las mujeres somos y fuimos una de las más violentadas, tanto de la esclavización como de la diáspora africana. Fuimos violadas y utilizadas en todos los sentidos, a nosotras se nos violentó el ser. Y así mismo, tenemos la característica de haber sido propulsoras de la resistencia, llevamos a la libertad a nuestro pueblo en casi toda Latinoamérica. (Entrevista Camila, 2014)

Durante la conformación de los Estados-nación, las africanas libres de esta zona pasaron a formar parte del Perú (1821). Ellas se dedicaban a trabajos de labores domésticas (como lavanderas y planchadoras), gastronomía y artesanía, principalmente. Sin embargo, este nuevo gobierno no las integró y continúo la discriminación contra aquellos que descendían de africanos/as. Posteriormente, los derechos de esta población se vieron nuevamente vulnerados debido a la "Guerra del Pacífico" (1879-1883) y el período de chilenización (1884-1929). Proceso que ha sido descrito por múltiples investigadores, como un momento de degradación física, psicológica y socio-cultural de quienes habitaban en Arica, ciudad que perteneció al Perú hasta el "Tratado de Ancón" en 1929, en el que Chile se queda con este territorio (Salgado, 2013). La chilenización fue un proceso violento, con muertes, amedrentamientos e imposiciones de costumbres chilenas ${ }^{18}$, tanto para negros y negras como para indígenas del lugar (Zapata, 2004). Esto fomentó mecanismos nacionalistas de un nuevo Chile idealizado, sin negros, muy emparentado a una ideología latinoamericana racista, patriarcal, segregacionista y clasista (Curiel, 2009).

\footnotetext{
${ }^{18}$ Como referencia señalar que las costumbres chilenas ya fueron colonizadas por las españolas, pero ahora repiten el patrón con las diferentes culturas que habitan el territorio.
} 
Las familias afroazapeñas se dividieron, la selección estaba dada ahora por sexo y edad: aquellos varones que pudieran votar debían ser eliminados del territorio, a través de asesinatos, exilios y/u obligación de hacer el servicio militar, como mecanismos acordes al proyecto político de adoctrinamiento para consolidar una soberanía nacional chilena (Alarcón, Araya y Chávez, 2017). En consecuencia, la constitución del parentesco nuclear perdió a hijos, hermanos, padres y adultos mayores. El hogar se rompió y para quienes se quedaron en la zona se convirtió en un espacio de rebelión y resistencia (Artal, 2012). Está en la memoria colectiva aquellos momentos en que venían grupos civiles armados, conocidos como "ligas patrióticas" o "ligas a favor de chilenos", quienes amedrentaban a la población peruana, mataban a los varones y violaban a las mujeres. Varios relatos de las participantes sostienen que sus ancestros le contaban que debían ocultarse junto a infantes y esperar entre matorrales, entretechos, cuevas o en baúles, para no ser encontrados. Los testimonios así lo ratifican:

En esa época mi abuelito tenía que elegir entre Chile o Perú y él escogió Perú, porque no quería perder sus raíces. Pero mi abuela no quería marcharse, así que se quedó acá en Chile junto a sus tres hijos y mi abuelo se fue solo. Existen muchas historias de este tipo, porque varias familias pasaron por lo mismo, se tuvieron que ir y el núcleo familiar se desarmó, para siempre. Nosotros no supimos nunca más de mi abuelo. (Entrevista Daysi, 2016)

Mi mamá siempre recordaba cosas y nos contaba. Las mujeres tuvieron un rol importante en la chilenización, porque fueron los hombres quienes tuvieron que irse y ellas se quedaban con los hijos, porque los hombres eran hombres muertos. Mi mamá fue perseverante y trabajadora, ella me dejó enseñanzas de vida, de cómo enfrentar las cosas, de entender de dónde vengo y a dónde tenía que ir. (Entrevista Azeneth, 2014)

Las redes y los lazos de parentesco de la comunidad afro son complejos, existen grupos parentales que están relacionados pese a tener una distancia genealógica y geográfica (entre Chile y Perú). En conjunto, como señala Campos (2018) existen formas de pigmentocracia nacionalistas e individuales, que se sustentan en las palabras de las colaboradoras al hablar de la idea de "mejorar la raza", cuestión que se materializó en que la mayor parte de las madres que quedaron viudas o que sus cónyuges fueron exiliados durante la chilenización, dispusieran a sus descendientes -especialmente a las mujeres- la idea de casarse con una persona de tez blanca. Las consecuencias de la chilenización fueron la noción de "blanqueamiento" y la negación de sus costumbres para evitar así futuras discriminaciones (Espinoza, 2015). Sin embargo, esta fase trae consigo el comienzo de la invisibilización y negación de las identidades negras que permanecieron en este espacio, así lo puntualiza también una colaboradora:

Las abuelas y las mamás siempre decían: tienen que casarse con un blanco para mejorar la raza. Si te veían con una pareja morena, se enojaban. Era fuerte eso porque incluso si algún joven negro me cortejaba a mí no me gustaba, porque me lo tenían metido en la cabeza. (Entrevista Marta, 2014) 
A pesar de que solicitaban ocultar sus rasgos físicos y sociales, también fomentaban la permanencia de sus culturas. Esto se ratifica en que las participantes recuerdan que sus madres los llevaban a lugares de reunión donde tocaban distintivos estilos de música y cocinaban alimentos como el mondongo ${ }^{19}$; también se acuerdan de fiestas religiosas: "Cruz de Mayo", "San Miguelito", "Virgen de las Peñas", "Pascua de Negros", "Ño Carnavalón", por nombrar algunas. A través de la manifestación de estas tradiciones se da cuenta de las construcciones sociales, culturales y simbólicas, que incluyen una pluralidad de expresiones, y se convierten en representaciones orales, inmateriales (o materiales) y performativas, que actúan como soportes significantes (Chávez, 2016).

En palabras de Salgado y Llerena, cultores afrochilenos/as, son: "las ancestras afroazapeñas [las] encargadas de conducir los clanes familiares y los modos de producción y vida, especialmente en los valles" (2019, p. 296), ello da cuenta de una particular situación en el valle de Azapa, donde se observa un patrón de vida de reproducción de los núcleos familiares rurales afro rodeado de mujeres, en el que podría haber un elemento identitario con bases materiales propias. Otro elemento importante es que gran parte de las y los participantes afroazapeños dice haber heredado sus tierras por línea materna, lo que reafirma lazos de parentesco de carácter matrilineal, esto quiere decir que la mayoría de las mujeres rurales ocupan los lugares de habitación que heredaron, sin existir una considerable movilidad de las mismas. Sin embargo, en las últimas décadas se ha dado una migración sustantiva a la ciudad de Arica por búsqueda de fuentes laborales y mejores condiciones de vida, por lo que varias parcelas del valle de Azapa se convierten en segundas residencias. A pesar de esto, se estima que en el valle existe una línea matrilocal, es decir, que la residencia del varón es en la tierra de la mujer, siendo ellos quienes cambian de localidad (Montecino, 1995). El lugar de procedencia del cónyuge suele tener dos posibilidades: a) del valle y ser indígena, afro o blanco; o b) fuera del valle y ser blanco. En el caso afroazapeño, los varones entraban a formar parte de la familia de las mujeres, por lo que sus posicionalidades eran menores pues estaban entre los parientes de su esposa. En conjunto estos elementos justifican, una vez más, la noción tan extendida en la comunidad sobre la relevancia de las "matriarcas".

\section{Comerciantas y artesanas en el valle de Azapa}

Son las madres y abuelas de las futuras lideresas de un movimiento que se iniciará en el futuro con el objetivo de visibilizar su existencia de mujeres afrodescendientes que trabajaron por el bienestar de sus familias y que viajaron por el desierto buscando el desarrollo y la existencia, pues su identidad es invisible en el relato de los redactores de la historia nacional. (Salgado y Llerena, 2019, p. 295)

La población femenina negra que permaneció en el valle de Azapa, cumplió el papel de convertirse en encargadas de la contención de un quebrado núcleo familiar y de la continuación de tradiciones, asimismo, ser sustentadoras económicas y administradoras del hogar, pues los varones fueron asesinados, torturados y/o exiliados (Barrenechea, 2015), y

\footnotetext{
${ }^{19}$ Comida que la comunidad afro adscribe como típica. El plato consiste en los interiores del animal. Recalcan que antiguamente las y los esclavizados debían comer lo que le sobraba a sus amos y con esos restos realizaban el "mondongo".
} 
ella adquirieron los roles de proveedoras y cuidadoras. Desde allí una primera tesis de por qué las mujeres quedaron a cargo, dando comienzo a un tipo de sistema matrilineal y de matriarcado. Una de sus principales fuentes de ingreso, fue el reconocido papel de "comerciantas"20".

\section{Imagen $\mathrm{N}^{\circ} 1$ : Mujeres bajando a burro con su mercadería.}

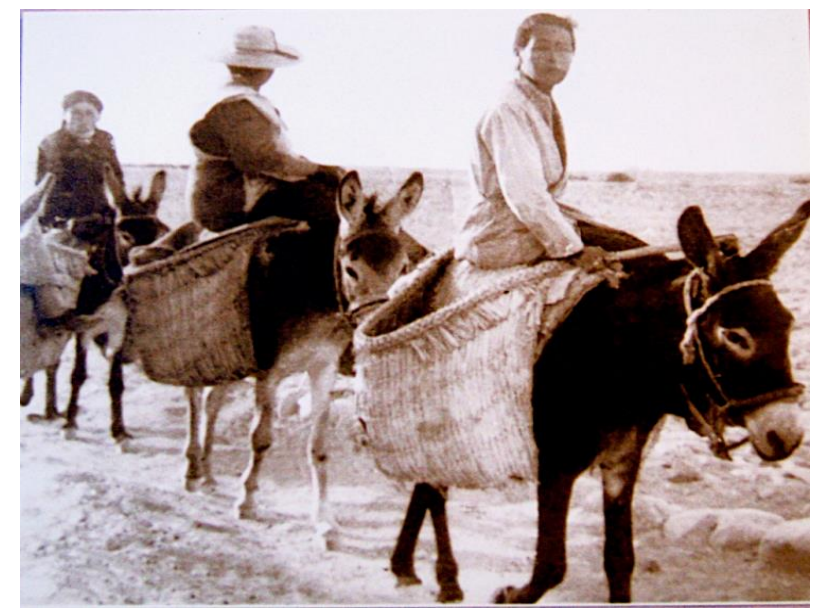

Fuente: Fotografía cedida por familia afrochilena.

Ellas eran agricultoras y ganaderas de burros. Las labores campesinas son parte de la subsistencia de quienes habitan el sector y que continúa hasta el presente como un soporte territorial e identitario, como herencia familiar ancestral (Chávez, 2016). Hubo un grupo de mujeres negras que realizaban transacciones comerciales y económicas de productos agropecuarios, se trasladaban a lomo de burro desde Azapa hasta Arica para vender frutas y verduras: lechugas, pepinos, cebollas, porotos verdes, pacay ${ }^{21}$, chirimoyas, naranjas, ciruelas, guayabas, dentro de una gran variedad de productos. Ello nos muestra su habilidad en lo comercial, que las convierte en agentes activas de lo agrícola y lo monetario. Dentro del recuerdo, los participantes revelan que sus madres y abuelas eran importantes no sólo en los roles de cuidados, sino que también en lo laboral y económico.

Mi mamá era comercianta, salía a vender a burro hasta Arica. Varias mujeres antiguamente se iban con burros y en "angarillas22" grandes llevaban naranjas, todo lo que se cultivaba, iban pasando parcela por parcela y ahí se encontraban con las que iban pa' Arica al mercado San Marcos. No había camiones antes. Ellas se levantaban temprano y llegaban allá, ella vendía todo, le iba bien. De 1930 mi mamá hizo esto. (Entrevista Lucía, 2014)

Mi abuelita era unas de las mujeres que traía las verduras y la leche de chivatas a la ciudad de Arica. Ella era súper entusiasta, las mujeres somos así hasta el día de

\footnotetext{
${ }^{20}$ Las y los afroazapeños usan este concepto para referirse a las mujeres que realizaban estas labores.

${ }^{21}$ Fruto que la comunidad afro reclama como propio.

${ }^{22}$ Es un tipo de receptáculo.
} 
hoy. Mi abuelita me enseñó a ser una mujer digna con valores y a entender y respetar que por mis venas corre sangre negra. (Entrevista Liliana, 2015)

La madre de la señora Lucía, realizó esta labor hasta 1952, después el viaje se realizaba en un camión fletero al que llamaban el "Chato Terraza", para ir a la feria de Arica e instalarse en la puerta del mercado San Marcos a vender. Lucía recuerda que una vez su madre la llevó y la escuchaba gritar: "¡Naranjas, naranjas, cómpreme caseritas!". Ella destaca que su madre era muy esforzada, pues debía ocuparse de las labores del hogar, ser madre, esposa y además comercianta, esto muestra un fuerte activismo en tanto al trabajo productivo como reproductivo. Tal como describe Evelyn Castro para el caso de las afrocostarricenses, "destacan su toma de decisiones en el hogar y el aporte en cuando a actividades realizadas y a nivel económico como fundamental para su autonomía femenina" (2006, p. 89). A través de estos relatos distinguimos cómo las mujeres fueron -y continúan siendo- importantes en su habilidad para gestionar un espacio tan significativo como la producción y venta de alimentos, para lograr un empoderamiento económico femenino.

Igualmente sobresale la confección de artesanía en totora, producto que traían desde el valle de Azapa y de Lluta, existen roles que se sostienen en el arte, el placer y el saber para crear comunidades (Curiel, 2007). Las afrochilenas heredaron estas habilidades, sobresaliendo hasta la actualidad en este oficio, fabrican canastos, esteras, sopladores de fuego, entre otros utensilios y decoraciones. Según los testimonios de las participantes, muchas casas fueron forradas con este material para protegerlas del clima y de robos, y la artesanía se posiciona como un elemento cultural de la comunidad afro, el cual ha sido rescatado dentro de la reconstrucción de sus dinámicas de identidad (Chávez y Araya, 2018). Si bien, la artesanía en totora fue utilizada principalmente para sobrevivir, igualmente era comercializada. La señora Rosa Guisa ${ }^{23}$, fue una cultora reconocida en esta labor y se encargó de transmitir su arte a generaciones posteriores.

\section{Lo culinario y el poder político afrofemenino}

Otro espacio importante es el culinario, según el INE (2013) un 10,1\% de la población afro señala que las comidas que preparan se posicionan como categoría de autorreconocimiento. Las maneras de cocinar y preparar los alimentos fueron heredadas, y a su vez, las traspasan a sus hijos e hijas, entre estos destacan el mondongo o picante de guatita, los picarones y alimentos elaborados con productos del mar. A través de esto advertimos otra tarea que realizan las mujeres afro, en sus roles como cocineras y transmisoras de una parte relevante de su cultura, no sólo en la producción de alimentos, sino que también en su distribución. Por último, cabe señalar que esta cocina es reconocida como parte de la comida peruana, pero la comunidad afro la adjudica como propia, dándole un matiz negro a lo culinario. Finalmente, tal como señalan las y los colaboradores:

La transmisión de las tradiciones generalmente se hace por las mujeres, ellas son capitanas en esas enseñanzas y raramente un hombre está vinculado así

\footnotetext{
${ }^{23}$ https://www.elmorrocotudo.cl/noticia/listado/arica-de-luto-fallecio-hija-ilustre-y-destacada-dirigentaafroazapena-rosa-gueisa-la (Visitado 9 de Julio, 2020)
} 
fuertemente. La verdad es que se requiere de una característica determinada y lo están haciendo ellas iy el favor que hacen a las nuevas generaciones, es tremendo! Es de vital importancia el mantener estas costumbres, y ellas son las que lo han cimentado desde las bases. (Entrevista Oscar, 2021)

Los roles femeninos han sido fundamental en la cultura afro, porque ella es la que logra mantener el círculo más íntimo, la cultura, y para callado, para que no se supiera, porque si no iban a ser discriminados. Las mujeres somos las que criamos, traspasamos ideas, creencias, vamos reproduciendo la identidad. (Entrevista Carolina, 2014)

Por último, sus roles como lideresas en la génesis del movimiento político son evidentes. En la conformación de organizaciones, lo intelectual y las comparsas socioculturales de Tumbe ${ }^{24}$, que sirven como visibilización de sus dinámicas (Salgado, 2015). Actualmente existen cuatro agrupaciones exclusivas de mujeres: Colectiva de Mujeres Luanda y Aluna Tambó en Arica; y la Red de mujeres rurales indígenas y afrodescendientes, e Hijas de Azapa en el valle. Estas agrupaciones luchan en espacios públicos contra la invisibilización, racismo y sexismo, para ello realizan seminarios, congresos y manifestaciones. Además, hay varias organizaciones que están lideradas por mujeres en sus comitivas: ONG Oro Negro, Tumba Carnaval, Arica Negro, ONG Lumbanga, entre otras. De esta manera, vemos que ellas tienen acceso a los espacios de poder debido a sus discursos políticos, estrategias y resistencias, quienes además se relacionan con entidades internacionales como la "Red de mujeres afrolatinas, afrocaribeñas y de la diáspora ${ }^{25 " . ~ E s t a ~}$ participación política las instala en un lugar donde han sido oprimidas y excluidas, tal como señala Kirkwood (1982), una historia escrita por hombres que sistemáticamente nos ha dejado invisibles y en silencio. Sentencia una colaboradora:

Las mujeres juegan un rol preponderante en la cultura de la matriz afrodescendiente acá en Chile y en el mundo, entonces ellas son quienes han guardado las tradiciones, por eso tienen el nombre de matriarcas, porque en el fondo han sido ellas las que han seguido la tradición, las que han sido cuidadoras, tanto del territorio como de las tradiciones y de la unión familiar, que hoy día son el baluarte para dar el sustento de la ley de reconocimiento en lo político. (Entrevista Marta, 2020)

\footnotetext{
${ }^{24}$ Las afro rememoran las labores de la esclavización y trabajo en la tierra, que representan en sus danzas, específicamente en el Tumbe, danza tradicional afrochilena (Letelier, 2015). Además: "el caso del Tumbe carnaval "rescatado" tiene así una función histórica: dar continuidad a una presencia negra o "afro" -con sus diversas nominaciones- en un territorio específico" (León, 2020, p. 80).

${ }^{25}$ Entre el 19 al 25 de Julio del año 1992, en República Dominicana se realizó el primer encuentro latinoamericano y caribeño de mujeres negras, allí se crea la "Red de Mujeres Afrolatinas, Afrocaribeñas y de la Diáspora".
} 


\section{Cruz de Mayo y matriarcado afroazapeño}

La "Cruz de Mayo" es una de las celebraciones religiosas más importante de la comunidad afroazapeña (Salgado, 2013). Es una mezcla de liturgias católicas, costumbres ancestrales indígenas y africanas, que se ha transmitido por generaciones, celebrada durante todo el mes de mayo y parte de junio en el valle de Azapa. Las y los colaboradores/as relatan que cada familia tiene una cruz, la cual los cuida y protege durante el año desde un cerro que forma parte de sus parcelas, por ello se hacen cargo de la veneración y posterior celebración de la misma. Cuando la cruz es puesta en el cerro, éste se convierte en un espacio sagrado, al mismo tiempo se realiza un tributo a la tierra para bendecir las futuras plantaciones, cosechas y cultivos de cada propiedad. El proceso consiste en bajar la cruz los primeros días de mayo para llevarla a que sea bendecida por un cura. Esto se realiza generalmente en la iglesia de San Miguel de Azapa, y luego cada familia la lleva a su espacio privado para velar y honrarla en un altar hasta la fecha estipulada para subirla de nuevo a su lugar de origen, y de este modo, renovar el ciclo. Esta peregrinación se realiza junto a cánticos y orquestas y culmina con una gran fiesta (Araya et al., 2019).

Este valle se convierte en un espacio-territorio identitario, en el que realizan sus actividades y prácticas, a través de su economía basada en el trabajo con la tierra, junto al desarrollo de sus continuum socioculturales, al igual que lo espiritual, simbólico y religioso. En específico, la "Cruz de Mayo" marca una organización activa de los núcleos familiares y del quehacer en comunidad, heredado por sus ancestros/as. En este artículo se sostiene que las cruces se han feminizado, pues poseen elementos que se asocian a la población femenina. En primer lugar, llama la atención que la mayoría de los nombres de las cruces sean de mujeres, pues históricamente son ellas quienes se han encargado de organizar la celebración, de ahí toma forma este matriarcado del valle de Azapa de las negras. Esto también puede estar ligado a que, según las y los participantes, mayormente las longevidades han sido de mujeres (Chávez, 2016).

Desde lo simbólico, las cruces de mayo son femeninas, pues desde su origen tienen relación con la pachamama o madre tierra, reivindican la fertilidad y las figuras de las ancestras. Según los testimonios y lo recopilado en terreno, desde antaño las mujeres afro se han dedicado a preparar los detalles tanto de la comida con platos especiales como de la festividad misma; vestir a la cruz y hacer los arreglos del altar, dirigir y organizar la fiesta, "la alegría e ímpetu (...) la lucha como trabajadoras y la ternura por reagrupar a la familia" (Araya et al., 2019, p. 25). De esta manera, las antiguas creencias en torno a los cerros tutelares se mantienen, a su vez como un homenaje hacia la figura femenina dadora de producción y abundancia, así se posiciona como símbolo a las antepasadas y al culto de la herencia que dejaron las abuelas protectoras (Chávez, 2016). En síntesis, encontramos una asociación a la cruz, a la virgen, a cerros, fecundidad y prosperidad, vinculadas a lo femenino.

Mi abuela y mi mamá nos encaminaron en este despertar, en la agrupación, eso nos abrió nuestra mente y corazón, de ver toda la riqueza que tenemos. Eso uno lo va aprendiendo y reconociendo. Yo les he enseñado también a mis hijos. Yo vengo de los negros, todos los azapeños somos negros, venimos de allá de la madre África, así me decía mi abuela. (Entrevista Vanessa, 2015) 
En concreto, ellas están a la cabeza en la preparación y resolución de esta festividad, también están encargadas de la sociabilidad extendida entre familiares, creyentes, amistades y descendientes que les acompañan en esta tarea. Por otra parte, en las directivas de las cruces de mayo constituidas actualmente como personalidades jurídicas, generalmente hay una presidenta mujer, fenómeno que como vimos anteriormente, se repite en el movimiento político, pues la mayoría son lideresas. Recalco la importancia que tienen las mujeres en esta fiesta, asimismo, se extrapola la experiencia a lo que sostiene Castro para el caso de las afrocostarricenses en el ámbito religioso, donde "ellas identifican claramente cómo esa vivencia espiritual (...) es un legado cultural que han recibido por sus abuelas y madres y estas por sus antecesoras, siendo una actividad y creencia transmitida por las mujeres negras" (2006, p. 82). Se puede sostener que el matriarcado afroazapeño es un tipo de organización donde las mujeres gozan de poder económico, político, de prestigio y sociocultural, poseen el carácter de jefas de hogar -tronco de las familias afro- y son quienes se destacan en los diferentes espacios analizados.

A continuación, mencionaré dos ejemplos de matriarcas del valle de Azapa y su relación con el territorio, sociabilidad y campo religioso, a partir de su afrodescendencia. Salgado y Llerena reconocen algunas: "Julia Corvacho, Rosa Guisa, Olga Llerena Corvacho, Rosa Ríos, Zulema Corvacho (...) Su rol central en el desarrollo de sus familias y comunidades ha sido heredado a las actuales dirigentes afrochilenas" (2019, p. 296).Esto podemos observarlo en lo religioso; las cruces relevan y honran el retrato femenino con el nombramiento de estas, ello se visualiza en los altares que poseen, generalmente, recursos del valle: arcos de ramas de sauce, diferentes frutas, flores y velas. Además, se pone una foto de todas aquellas consideradas como "matriarcas del valle" (Chávez, 2021).

\section{Imagen N² y №3 Fotografías Flora Cardoso}
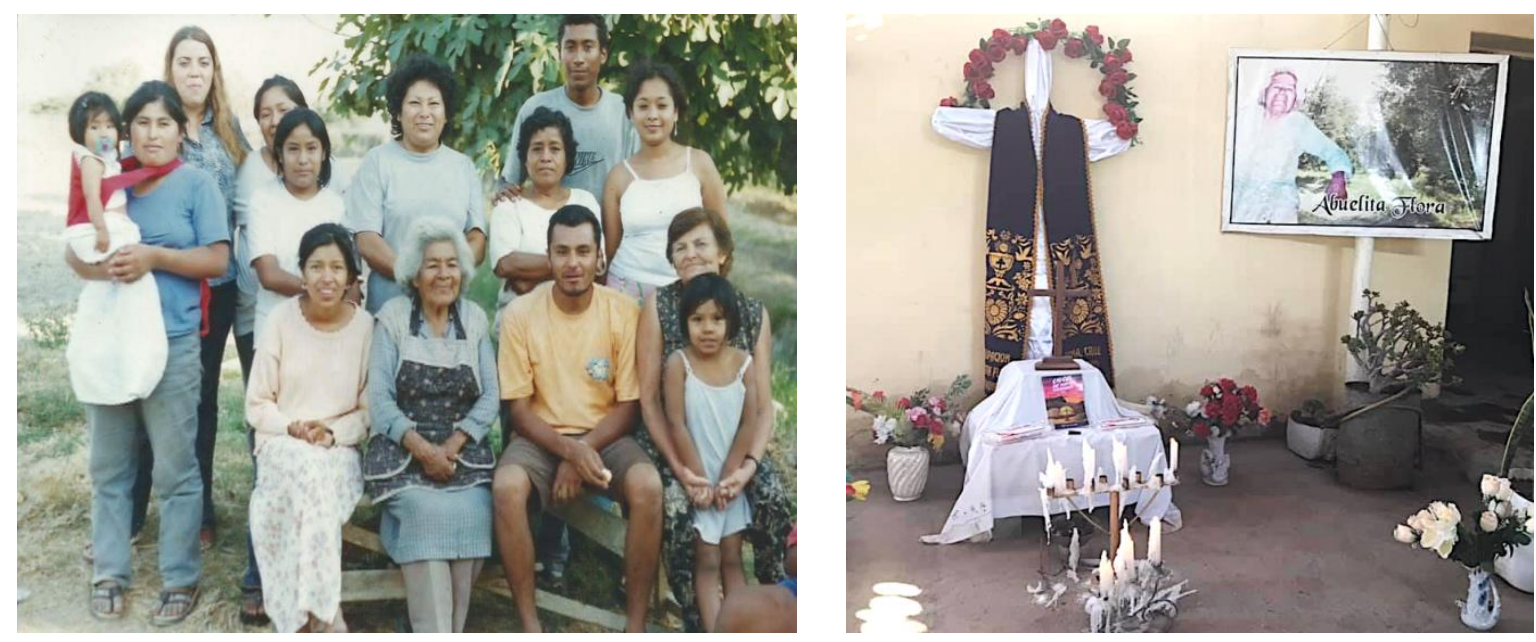

Fuente: Ambas fotografías fueron donadas por Carlos, parte de la Familia Cardoso. La abuela Flora está sentada en medio de sus parientes. En la otra observamos el altar de la Cruz de Mayo y una fotografía de ella. 
Esta cruz está en el Cerro Blanco, en el kilómetro 25 del valle de Azapa, es considerada una de las más antiguas, las y los participantes señalan que es celebrada desde hace unos sesenta años. La familia tiene una organización con personalidad jurídica, que incluso los adueña del cerro en la que instalan la cruz y también poseen una capilla propia que se llama "Santa Elenita". La abuela Flora Cardoso tuvo siete hijos y falleció a los 102 años, y era casada con Fernando Corvacho, "mi abuelito era súper negrito, mi abuela era morena, pero tenemos la sangre por ambos lados" (Entrevista Paola, 2020). Ella le pidió permiso a su madre para tener su propia Cruz de Mayo, porque estaban alejados y a veces no podían participar. Una nieta cuenta que, en el año 1964, Flora decidió hacer su propia cruz, "trabajó muchos años en la parcela, entre los tres se dedicaron a hacer la fiesta y hasta ahora hemos festejado" (Entrevista Paola, 2020). Otra mujer recuerda: "para mi tía Flora era su tradición, que estuviera todo y que no faltara nada. Ella siempre estaba atenta, se dedicaba al 100\%" (Entrevista Nélida, 2021). De este modo, vemos que el papel de las abuelas es central y está en relación con el vínculo que establecen con las posteriores generaciones, como cultoras de los conocimientos y saberes de sus pueblos.

\section{Imagen $N^{\circ} 4$ y $N^{\circ} 5$ Fotografías Julia Corvacho}
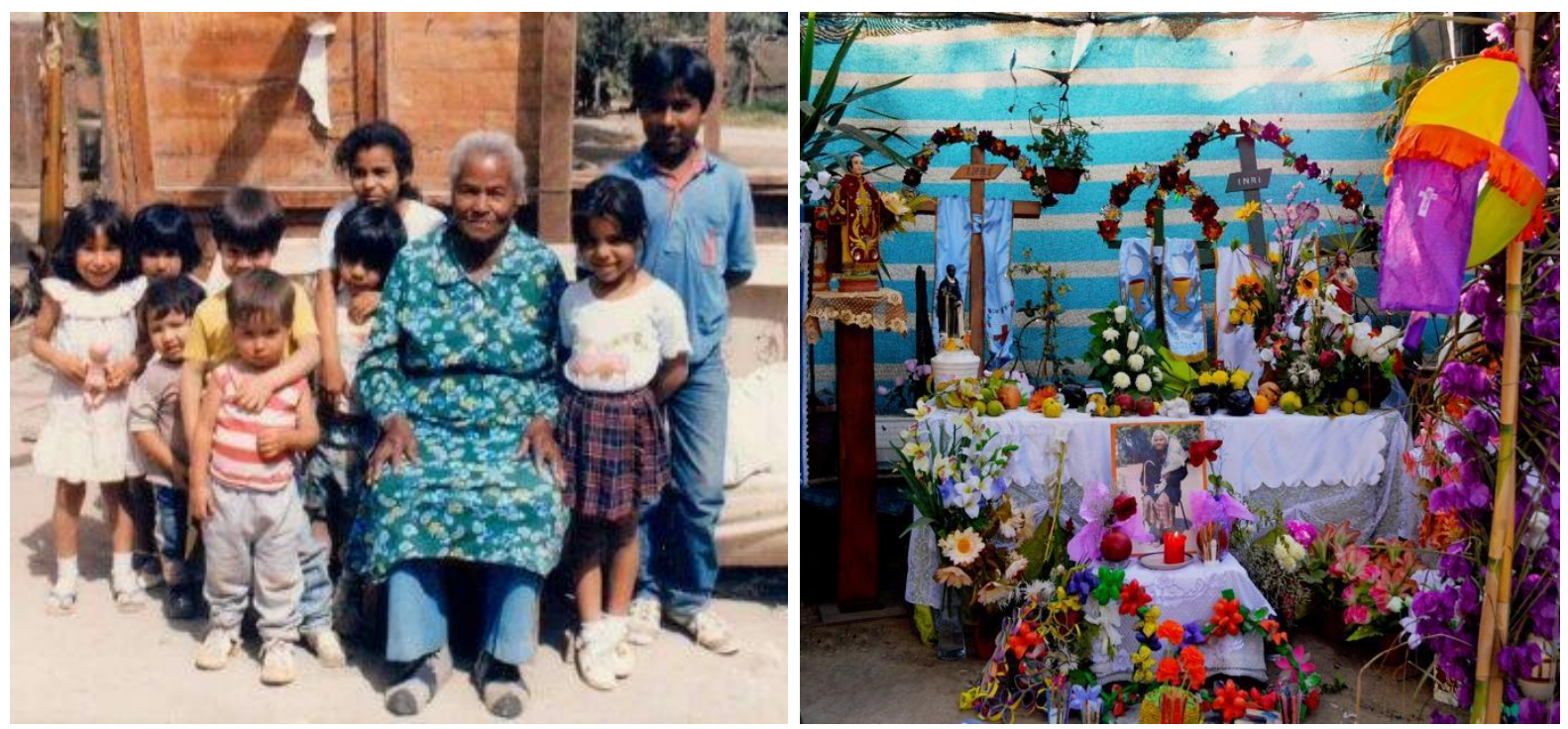

Fuente: La primera fotografía fue donada por la familia Corvacho, vemos a Julia rodeada de nietas y nietos. La segunda es el altar de las cruces de Mayo. Fotografía de la autora, 2014.

Julia Corvacho era una mujer del valle, su piel era de color aceituna en la que afloraba la herencia africana, como en tantos otros habitantes de Azapa (Araya et al., 2019). Varios resaltan su personalidad y recuerdan que siempre decía: "Yo soy negra, no afro. ¿Qué es eso afro? Yo soy azapeña... Azapeña neta" (Entrevistas, 2018). Julia Corvacho se ha convertido en un ícono para la cultura afro, considerada la matriarca del valle, quien murió a los 104 años de edad. De hecho, existe una agrupación llamada "Club Adulto Mayor Julia Corvacho", en el que se reúnen abuelos y abuelas de la comunidad para rescatar los relatos y memorias de los más longevos. "La abuelita Julia era una matriarca de las más antiguas del valle y nosotros tenemos que hacer perdurar su nombre" (Entrevista Rita, 2018). Esta mujer representa el 
tronco familiar de "La Corvachada", en la parcela del km. 8, donde sus descendientes se encargan todos los años de preparar la festividad que ella misma les inculcó hasta el momento de fallecer. Aquí advertimos nuevamente la importancia del linaje femenino y la constancia de mantener tradiciones para que sus descendientes las continúen. Los testimonios relatan, "era una señora que mantuvo la cultura y es la matriarca de Azapa. Le hacen honor a la vida que llevó ella" (Entrevista Arturo, 2014). De esta manera, Julia se ha convertido en una de las figuras femeninas más importantes para la historia local y el movimiento afrochileno, representa la fortaleza de una mujer orgullosa de su negritud.

\section{Reflexiones matriarcales}

Mediante las recopilaciones bibliográficas y testimonios de las y los afro, se evidencia un matriarcado debido a lo expuesto en cuanto a las relaciones de género, de parentesco, su vinculación con diferentes espacios de memorias desplegados, la relevancia en la celebración de la Cruz de Mayo, y los impactos socio-políticos como mujeres afrochilenas. En primer lugar, las mujeres negras en Chile han mantenido una comunidad viva pese a los intentos de invisibilización, mediante diversas prácticas de resistencias, articuladas en la trasmisión de sus memorias, culturas e identidades, explicitados en el caso particular de las cruces. $Y$ en segundo, en aspectos intelectuales, de autoridad, agencia y sujetas como lideresas del movimiento político afrochileno, que producen cambios estructurales en cuanto a la dominación femenina en sus comunidades, evidenciado en sus aportes en diferentes organizaciones.

Aquí he presentado diferentes estrategias de reivindicación que recaen más en las mujeres que en los varones, específicamente en los medios de transmisión entre sus descendientes, a través de dinámicas de memorias que dejan entrever un poderío y linaje femenino. Las esclavizadas africanas y las descendientes, según los testimonios, "han vivido siempre en un matriarcado $26 "$, que las lleva a estar en lo organizativo, participativo, productivo y reproductivo, como también en diferentes aspectos como cultoras. En los testimonios, se palpa un profundo conocimiento de la historia de las negras esclavizadas, pues manejan una amplia información sobre las labores que sus ancestras realizaban, incluso, al referirse a ellas, dicen "fuimos" como parte de sus historias, a pesar de la lejanía temporal. Las afrochilenas se apropian de este discurso pues reivindican un pasado esclavizado y lo realizado por sus ancestras, aunque ello signifique consecuencias discriminatorias en el contexto actual. Normalmente, ponen énfasis en que sus ancestras lucharon por mantener los lazos de parentesco de sus grupos familiares, se convierten en heroínas en las que se ven reflejadas, lo cual favorece el desarrollo de continuidades de poderíos femeninos en la comunidad afrochilena. Esto es algo que se ve hasta la actualidad en las comunidades afrochilenas de la ciudad de Arica -muy relacionado a lo político- pero sobretodo en el valle de Azapa en una infinidad de aristas, como el ejemplo de la Cruz de Mayo. Por medio del proceso del auto-

\footnotetext{
${ }^{26}$ Entrevista a Marta Salgado realizada por la Uchile. Ver https://www.uchileindigena.cl/marta-salgadoel-trabajo-de-las-mujeres-indigenas-con-las-afrodescendientes-tiene-que-estar-ligado-para-derribarlo-que-el-colonialismo-dejo-en-nosotras/ (Visitado 5 marzo, 2021)
} 
reconocimiento y autoidentificación afrodescendiente del norte de Chile, vemos un acervo femenino importante, tanto en lo sociocultural como en las organizaciones políticas.

El presente artículo contribuye a resignificar la importancia de estas mujeres que inculcaron diversas tradiciones a futuras generaciones. La permanencia de las afrodescendientes les da un significado diferencial en términos de la participación masculina, en el traspaso de la ancestralidad o las vinculaciones familiares, entendidas como redes extensas de relaciones sociales y de parentesco, permitiendo que la comunidad afro se constituya como tal. Las afrochilenas están involucradas con la vida comunitaria y el orden cultural, la socialización de sus infantes; han mantenido las redes familiares, de apoyo mutuo, y como hemos visto, ceden su patrimonio cultural a sus descendientes. Además, no han estado solamente replegadas a lo doméstico, quehaceres maternales y lo íntimo, igualmente se han inmiscuido en el ámbito público. Las afrochilenas han adquirido roles importantes en lo laboral, en la agricultura, en la artesanía, en espacios productivos y profesionales, y en un máxime percibido en la (re) construcción de las dinámicas de identidades y las memorias, desde lo privado a lo público, que les otorga un mayor reconocimiento social. Tal es su relevancia que el día 25 de Julio se instauró como el "Día Internacional de las mujeres afrodescendientes", celebrado tanto en Arica como en el valle de Azapa.

Estamos frente a mujeres que luchan, que se preocupan por sus familias y descendientes. Ellas quieren transmitir un mensaje y conocimiento de sus dinámicas y prácticas identitarias, pese a las injusticias, la falta de valoración del dolor y del momento de negación por el que pasaron, pues han sido discriminadas, despojadas de dignidad y de su identidad, a pesar de ello se reconstituyeron y se recuperaron a sí mismas y a su comunidad. Por esto el proceso de auto-reconocimiento es tan importante dentro de sus procesos vitales de vidas. Las prácticas y costumbres fueron invisibilizadas desde adentro y desde afuera, aunque en lo más íntimo se replicaban; los de la ciudad lo hicieron con mayor fuerza, ya que los del valle camuflaron algunas de estas características bajo el sello de pertenecer a lo rural, considerándose simplemente "azapeños/as".

Son múltiples los roles que han adoptado las afro en el valle de Azapa y en Arica. Estas mujeres desde el tiempo de la colonia utilizaron diferentes estrategias para sobrevivir y ayudar a su comunidad, además se enfrentaron de manera directa e indirecta al sistema político, judicial y social. Ellas cumplen un importante rol en la producción y reproducción cultural y la autoconciencia de la comunidad, en tanto que se encargan de difundir y transmitir, además deconstruir y reconstruir diferentes elementos que conforman sus identidades basadas en las tradiciones, técnicas culinarias, organizaciones políticas, bailes y cantos que hacen de la memoria una comunicación dinámica, efectiva y visible. En este artículo, en específico, se exploró cómo las cruces respaldan una visión de matriarcado pues generalmente éstas adoptan nombres de antepasados/as y se visualiza por medio de sus fotografías, destacando que la mayoría son abuelas. De esta manera, los lazos de parentesco se ven reflejados en este linaje femenino que cobra aún más sentido durante la celebración de la Cruz de Mayo.

Una de las hipótesis de este matriarcado afroazapeño, encuentra su origen en que durante la chilenización los hombres se fueron o los mataron, las negras permanecieron y se 
convirtieron en protectoras. Se encargaron de la contención del núcleo quebrado, continuaron con las tradiciones y la mantención de los hogares. Las afro fueron - y son- las que llevan el orden, la administración, toman decisiones y se convierten en sustentadoras de las producciones, economías familiares y la cohesión del grupo. De la misma forma, han iniciado un camino de politización desde sus roles como madres, esposas e hijas, y ligan estos perfiles a sus acciones políticas, convirtiéndose en dirigentas del movimiento afro. Dentro de lo privado y lo público, ellas poseen una mezcla de ambos mundos de forma continua, en el cual no han tenido obstáculos concretos para ingresar. En conclusión, las mujeres afrochilenas ostentan poder y destacan tanto en los ámbitos sociales, culturales, políticos, económicos e intelectuales. En este caso se contradice a Simone de Beauvoir (1999) al establecer que aún en el siglo XX, las mujeres estarían en labores fijas y rutinarias, pues las afro entran al mundo religioso y político de la trascendencia -eminentemente masculino- donde crean y construyen futuro.

De esta manera, dar a conocer la historia y la importancia de las afrochilenas en particular, resulta esencial, pues a diferencia de otros países de América Latina, en nuestro país hay un alto desconocimiento de la historia, identidades y procesos políticos a nivel sociocultural de esta comunidad, que propician relaciones de opresión, racismo y sexismo. Asimismo, apunto a la visibilización de las mujeres como parte de sus comunidades, con el fin de construir relaciones que valoren el parentesco, género y religión afro en Chile. Finalmente, la idea de un matriarcado se sostiene por los relatos de las y los colaboradores de esta investigación, sin embargo, no se puede extrapolar a toda la comunidad afrodescendiente, por lo que aún queda trabajo por realizar, sobre todo basado en futuras genealogías que sustenten esta discusión. Sin embargo, más allá de la validez de un matriarcado o no, luego de evaluar ciertos procesos estructurales vemos que se ajustan a la definición expuesta teóricamente, pues crean condiciones sociales que sustentan el desarrollo de prácticas políticas y socio-culturales matriarcales de las mujeres afrodescendientes en Arica y especialmente, en el valle de Azapa.

\section{Bibliografía}

Alarcón, J., Araya, I., \& Chávez, N. (2017). Identidad Negra en tiempos de chilenización: memorias de abuelos y abuelas afrodescendientes de Arica y valle de Azapa. Santiago de Chile: Ministerio de Cultura.

Annunziata, R. (2021). Bachofen y el retorno de las Madres. Acta Poética, (30), pp. 273-293.

Araya, I., Chávez, N., \& Alarcón, J. (2019). Cruz de Mayo Julia Corvacho; el legado negro del valle de Azapa. Santiago de Chile: Ministerio Culturas y Artes. 
Ardito, L. (2021). ¿Feminismos "amefricanos"?: Trayectorias políticas e intelectuales de Lélia González y Alicia Camacho durante la década de 1980. Meridional. Revista Chilena de Estudios Latinoamericanos,(16), pp. 180-212.

Artal, N. (2012). A(f)rica: relatos y memorias afrodescendientes en Arica tras la chilenización y el conflicto entre Perú y Chile (1883-1929). Aletheia, (4), p. 1-16.

Bachofen, J. (1998). I/ matriarcato. Torino: Einaudi.

Barrenechea, P. (2005). María Antonia, esclava y músico: la traza de un rostro borrado por/para la literatura chilena. Atenea, (9), pp.87-98.

Beauvoir, S.(1999). El segundo sexo. Buenos Aires: Sudamericana.

Briones, V. (2007). Mujeres Afrodescendientes en el corregimiento de Arica, siglo XVIII. De un silencio negro a la batalla por la libertad. Revista Ciencias Sociales, (19), pp. 7-25.

Carneiro, S. (2001). Ennegrecer al Feminismo; Brasil. Ponencia presentada en el Seminario La situación de la Mujer negra en América Latina, desde una perspectiva de género.

Castro, E. (2006). Representaciones contemporáneas de la esclavitud en las mujeres Afrocostarricenses, desde sus propias voces. Tesis Magíster en estudios de Género y Cultura. Santiago de Chile: Universidad de Chile. 
Campos, L. (2018). Los negros no cuentan. Acerca de las demandas de reconocimiento de los afrodescendientes en Chile y la exclusión pigmentocrática. Antropologías Del Sur, (8), pp.15-31.

Chávez, N. (2016). Mujeres afrodescendientes de Arica y el valle de Azapa, raíces africanas en el norte de Chile. Tesis Licenciatura en Antropología. Santiago de Chile: Universidad Academia de Humanismo Cristiano.

Chávez, N. (2021). Intelectualidad, raza y género: mujeres en afro-resistencia del valle de Azapa y Arica, Chile. Meridional. Revista Chilena de Estudios Latinoamericanos, (16), pp. 213-237.

Chávez, N. (2021). Cruz de Mayo afroandina: prácticas religiosas y dinámicas identitarias afrodescendiente y aymara en el valle de Azapa, Arica, Chile. Tesis Magister en Antropologías Latinoamericanas. Santiago de Chile: Universidad Alberto Hurtado.

Chávez, N., \& Araya, I. (2018). Mujeres de Colores; historias femeninas afro andinas. Santiago de Chile: Ministerio de Cultura.

Cortés, C., \& Rivera, C. (2019). Desde las ancestras a la actualidad. Mujeres negras de Arica y sus resistencias. Arica: Ministerio Cultura y Artes.

Curiel, O. (2007). Los aportes de las afrodescendientes a la teoría y la práctica feminista. Desuniversalizando el sujeto <Mujeres>, Perfiles del Feminismo Iberoamericano, (3), pp. 1-18.

Curiel, O. (2009). Descolonizando el feminismo: Una perspectiva desde América latina y el Caribe. Primer Coloquio Latinoamericano sobre Praxis y Pensamiento Feminista. Buenos Aires: Argentina. 
Revista Punto Género N ․ 16 Diciembre de 2021

ISSN 2735-7473 / 119- 144

Curiel, O. (2017). Género, raza, sexualidad. Debates contemporáneos. Intervención en Estudios Culturales, (4), pp. 41-61.

Davis, A. (2004). Mujeres, raza y clase. Madrid: Akal.

De la Cadena, M. (1992). Las mujeres son más indias: Etnicidad y género en una comunidad del Cuzco. Revista Isis Internacional: Ediciones de las Mujeres, (16), pp.25-45.

Espinoza, M. (2015). Afrochilenos en Arica: Identidad, organización y territorio. Antropologías del Sur, (3), pp. 175-190.

Espinosa, Y. (2014). Una crítica descolonial a la epistemología feminista crítica. El Cotidiano, (184), pp. 7-12.

Espinosa, Y. (2016). Y la una no se mueve sin la otra: descolonialidad, antirracismo y feminismo. Una trieja inseparable para los procesos de cambio. Revista venezolana de Estudios de la Mujer, (46), pp.47-64.

Guber, R. (2014). Prácticas etnográficas. Ejercicios de reflexividad de antropólogas de campo. Buenos Aires: IDES, CAS.

Hall, S (1995). Negotiating Caribbean identities, en New Left Review, (209), pp. 3-14.

Hernández, C (2019). Black Women's Struggles against Extractivism, Land Dispossession, and Marginalization in Colombia. Latin American Perspectives, (2), pp. 217-234.

Hill Collins, P (1998). La política del pensamiento feminista negro, en Navarro Marysa (comp). ¿Qué son los estudios de mujeres?. Buenos Aires: Fondo de Cultura Económica. 
Instituto Nacional de Estadísticas de Chile. (2013). Encuesta de Caracterización Afrodescendiente. Santiago de Chile.

Kirkwood, J. (1982). Ser política en chile: las feministas y los partidos. Santiago de Chile: FLACSO.

Klein, H. (1986). La Esclavitud Africana en América Latina y el Caribe. Madrid: Alianza Editorial.

Lamas, M. (1986). La Antropología feminista y la categoría de género. Nueva Antropología, (30), pp.173-198.

Lassiter, E. (2005). The Chicago Guide to Collaborative Ethnography. Chicago: University of Chicago Press.

León, M. (2020). Movimientos en el 'movimiento'. reflexividad y performance de una presencia afrodescendiente en Arica (Chile). Boletín del museo chileno de arte precolombino, (25), pp. 67-82.

Letelier, C. (2015). ¡Soy Afroariqueña!. Rufián Revista, (21), pp. 1-3.

Lugones, M. (2008). Colonialidad y género. Tábula Rasa, (9), pp. 73-101.

Machado, S. (2009). Amas mercenárias: o discurso dos doutores em medicina e os retratos de amas - Brasil, segunda metade do século XIX. Hist. Ciencias aude Manguinhos, 16 (2), pp. 305-324. 
Mendizábal, I.(2012). La lengua y lo afro: de la literatura oral a la oralitura. Chasqui Revista Latinoamericana de Comunicación política y pueblos indígenas, (120), pp. 93-102.

Montecino, S (1995). Sol viejo, sol vieja. Lo femenino en las representaciones Mapuche. Colección mujeres en la cultura chilena. Santiago de Chile: Servicio Nacional de la Mujer.

Martín-cano, F. (2005). Estudio de las sociedades matrilineales (S. M.) Nómadas. Critical Journal of Social and Juridical Sciences, 22 (2), pp. 1-10

Rivera Cusicanqui, S. (2010). Una reflexión sobre prácticas y discursos descolonizadores. Buenos Aires: Tinta Limón.

Salgado, M. (2013). Afrochilenos. Una historia oculta. Arica: Herco Editores S.A.

Salgado, M. (2015). Crónica del Movimiento Pueblo Afrochileno: La lucha por el reconocimiento constitucional. Rufián Revista, (21), pp. 1-3.

Salgado, M. \& Llerena, M. (2019). Memorias marginadas del pueblo afrodescendiente chileno: la restitución de la identidad. Anales de la Universidad de Chile, (16), pp. 293-298.

Segato, R. (2010). Género y colonialidad: en busca de claves de lectura y de un vocabulario estratégico descolonial. En Quijano, Aníbal y Mejía Navarrete Julio (eds.): La Cuestión Descolonial. Lima: Universidad Ricardo Palma.

Soto, R. (1992). Esclavas negras en Chile colonial. Santiago: Bravo y Allende Editores. 


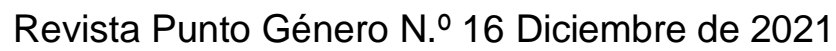

ISSN 2735-7473 / 119- 144

Soto, R. (2001). Mujeres negras: sexualidad, enfermedad y salud en el Chile colonial. Revista Ciber Humanitatis, (19), pp. 1-7.

Katzer, M., \& Samprón, A. (2011). El trabajo de campo como proceso. La etnografía colaborativa" como perspectiva analítica. Revista Latinoamericana de Metodología de la Investigación Social, (2), pp. 59-70.

Zapata, C. (2004). Atacameños y Aymaras. El desafío de la "verdad histórica". Estudios atacameños, (27), pp. 169-187. 